\title{
TWEETSTORMS E PROCESSOS DE (DES)LEGITIMAÇÃO SOCIAL NA ADMINISTRAÇÃO TRUMP
}

\author{
Dale Koike ${ }^{1}$ \\ Anna Christina Bentes ${ }^{2}$
}

RESUMO: Neste artigo, argumentamos que os processos de (des)legitimação de determinadas práticas de linguagem, temáticas e perspectivas performatizadas pelos tweets do presidente americano Donald Trump consideram fortemente a condição de reflexividade dos atores dos mais diversos campos sociais. Nossa principal hipótese é a de que os tweets de Donald Trump mais repercutidos pela própria imprensa americana e pelos meios políticos são os que buscam legitimar, com base na autoridade pessoal do presidente, práticas discursivas antirreflexivas. De forma a dar conta dessa tarefa, observamos a produção dos tweets por parte de Donald Trump durante um período de 35 dias e classificamos tematicamente essa produção. Os resultados das análises mostram que, apesar de não serem repercutidos pela mídia comercial americana, a maioria dos tweets do presidente Donald Trump, mesmo cumprindo funçóes prototípicas, de fato legitimam toda uma agenda antirreflexiva.

Palavras-chave: Tweets. Donald Trump. Temáticas. Reflexividade social. Legitimação social.

${ }^{1}$ Universidade do Texas - Texas, Austin, Estados Unidos. E-mail: dalekoike@gmail.com ${ }^{2}$ Universidade Estadual de Campinas - Campinas (SP), Brasil. E-mail: annafapesp@hotmail.com DOI: $10.1590 / C C 0101-32622018183528$ 


\title{
Tweetstorms and processes of social (de)legitimation in the Trump administration
}

\begin{abstract}
Through this article, we argue that the processes of social (de)legitimation of certain language practices, themes, and perspectives found in the current U.S. President Donald Trump's tweets strongly demonstrate the reflexivity condition of the actors from the most diverse social fields. Our main hypothesis is that Donald Trump's tweets discussed widely in the American press and in the political arena are those that seek to legitimize anti-reflexive communicative practices based on the President's personal authority. We observed the 'tweetstorms' performed by President Donald Trump during a period of 35 days and we categorized this production according to its topics. The results of such analysis show that although most of President Donald Trump's tweets are not publicized by the American commercial media, and although his tweets perform prototypical functions, they do legitimize an antireflexive agenda.
\end{abstract}

Keywords: Tweets. Donald Trump. Themes. Social reflexivity. Social legitimation.

\section{INTRODUÇÃO}

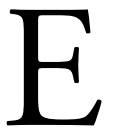

m 21 de junho de 2017, em uma matéria de Julie Bykowicz (2017) publicada pela Associated Press, afirma-se que as "tempestades de tweets" (tweeststorms) produzidas pelo atual presidente dos Estados Unidos Donald Trump, desde que assumiu a Presidência em janeiro de 2017, a partir de suas contas no Twitter, destroem definitivamente as "conferências de imprensa" da Casa Branca. Em outras palavras, a matéria afirma que as formas tradicionais de transparência e comunicação da Casa Branca foram substituídas por uma comunicação direta e de mão única por parte do presidente Donald Trump, representada pela produção de tweets e de discursos para audiências amigáveis. Ainda segundo a matéria, Donald Trump não concedia (até 21 de junho de 2017) entrevistas para a imprensa há mais de um mês. Nesse senti- 
do, é possível afirmar que Trump, com pouco mais de quatro meses à frente da Presidência dos Estados Unidos, transformou o uso de contas no Twitter na mais direta forma de comunicação com seus seguidores ${ }^{1} \mathrm{e}$ com o público norte-americano em geral, dando continuidade às práticas comunicativas performatizadas na campanha presidencial de 2016.

De forma a ilustrar essa questão, vejamos três tweets a partir da conta @realDonaldTrump postados no período por nós selecionado para a elaboração das reflexôes feitas neste artigo. O primeiro é de 12 de maio de 2017, no qual Trump cogita:

(1) Não seria melhor cancelar todas as conferências de imprensa e passar a escrever respostas pelo bem da precisão?2

Para a analista americana Kathleen Hall Jamieson, citada na matéria de Bykowicz, o público, ao ler os tweets do presidente Donald Trump, tem acesso a "asserçôes" e não a "argumentos"; a "ataques" e não a "justificativas". Em 17 de maio de 2017, Trump produziu o seguinte tweet.

(2) Melhor que James Comey reze para que não haja "fitas" de nossas conversas antes que ele comece a vazar para a imprensa ${ }^{3}$.

Esse último tweet causou enorme repercussão nos meios políticos e jornalísticos norte-americanos porque, a partir dele, pode-se inferir que o presidente Donald Trump gravou suas conversas com o entáo diretor do FBI James Comey. Esse tweet também está indiretamente relacionado à questão da possível interferência da Rússia nas eleiçóes presidenciais norte-americanas de 2017, a qual teria sido possibilitada pelo entáo candidato republicano Donald Trump. O promotor especial Robert Mueller, agindo independentemente do atual Departamento de Justiça, foi nomeado para iniciar investigaçóes sobre essas possíveis conexóes da campanha presidencial de Trump com autoridades russas. Os políticos responsáveis pela investigaçáo do tema no Senado e no Congresso norte-americanos deram indícios de que esse tweet poderia ser interpretado como uma "ameaça" do presidente a James Comey. Em 18 de maio de 2017, Trump reagiu da seguinte forma: 
(3) Esta é a única caça às bruxas de um político na história americana!

O uso do Twitter como forma de comunicação entre o público e a Casa Branca dos Estados Unidos e o público em geral foi implementado pelo antecessor de Donald Trump, o presidente Barack Obama, responsável pela criação da conta no Twitter @POTUS (President of the United States), que apresentava os posicionamentos da Casa Branca sobre vários assuntos. Por meio dessa conta, a administração democrata emitiu breves resumos de suas principais preocupaçóes, os quais eram cuidadosamente redigidos por escritores profissionais para refletir as políticas e opinióes da Presidência dos Estados Unidos e, somente depois de muitos filtros, enviados para divulgação em várias mídias. No entanto, a conta @POTUS usada pelo atual presidente Donald Trump, e sua conta pessoal @realDonaldTrump, apresentam um comportamento completamente diferente daquela usada por Barack Obama durante sua gestáo, conforme atesta a jornalista Amber Phillips, em artigo publicado em 06 de junho de 2017 no Washington Post:

Náo há vetos de advogados (pelo menos não que a deputada e secretária de Imprensa da Casa Branca Sarah Huckabee Sanders esteja ciente), não há vetos do staff de Comunicação. É apenas o presidente e seu iPhone, falando em nome de toda a Casa Branca 5 .

Muitas vezes, os tweets de Donald Trump são publicados às 2 ou $3 \mathrm{~h}$ da manhá, o que permite suposiçôes de que ele estaria escrevendo simplesmente o que vem à sua cabeça. Isso parece construir a imagem de que Trump expressa suas opinióes diretamente ao público dos Estados Unidos, livre das camadas de escritores e censores que normalmente cercam essa autoridade.

Em 29 de abril de 2017, logo após a eleição de Donald Trump como presidente dos Estados Unidos, o site Mashable.com relatou que suas duas principais hashtags foram \#MAGA (Make America Great Again) e \#AmericaFirst, indicando que a maioria dos tweets foram ecos de sua campanha, sendo que as palavras mais usadas foram "grande" e "América/americano". 
O uso do Twitter por Donald Trump, antes mesmo de chegar à Presidência dos Estados Unidos, pode ser observado no arquivo maciço de seus tweets (TRUMP TWITTER ARCHIVE). O site divide o arquivo por temas que ocorrem mais comumente em seu discurso. Por exemplo, no momento da escrita deste artigo, "notícia falsa" aparece em 206 tweets; "Obama” é mencionado 90 vezes; e seu debate com a grande mídia comercial norte-americana aparece em mais de duas centenas de postagens. Nos tweets de Trump, a grande mídia é constantemente acusada de não retratá-lo com precisão e justiça. $\mathrm{O}$ arquivo também mostra que ele usa adjetivos negativos para categorizar outras personalidades. Os cinco adjetivos mais comuns são: "perdedor", "mudo" ou "manequim", "terrível”, "estúpido" e "fraco".

Esses levantamentos indiciam que as ações linguístico-discursivas de Trump como candidato, mas, mais especialmente, como recém-eleito presidente dos Estados Unidos, buscam legitimar determinadas práticas de linguagem, temáticas e perspectivas. Nesse sentido, um pressuposto deste trabalho está de acordo com a formulação de Bourdieu (2004), para quem os processos de legitimação de determinada variedade linguística e a manutenção dessa legitimidade pressupóem um trabalho permanente de correção, do qual se incubem tanto os locutores singulares como as instituiçóes especialmente organizadas para essa finalidade. A nosso ver, o foco sobre os processos de legitimação social envolve necessariamente a compreensão do papel não apenas dos recursos linguísticos, mas, especialmente, das estratégias de produção textual-discursiva na manutenção da legitimidade conquistada pelos atores sociais (BOURDIEU, 1983) no interior de determinado campo social.

Neste artigo, argumentamos que os processos de (des)legitimação de determinadas práticas de linguagem, temáticas e perspectivas performatizadas pelos tweets do presidente Donald Trump consideram fortemente a condição de reflexividade ${ }^{6}$ dos atores dos mais diversos campos sociais em relação a essas mesmas práticas. A nosso ver, o Twitter, a partir da eleição de Donald Trump, foi definitivamente legitimado como a principal fonte de acesso às atuais perspectivas da Presidência dos Estados Unidos, sendo que a natureza de tal legitimaçáo, no caso da conta @realDonaldTrump, pode ser analisada com base em teorias sociais e discursivas sobre o fenômeno da reflexividade nas sociedades pós-modernas. 
Nossa principal hipótese é a de que os tweets de Donald Trump mais repercutidos pela própria imprensa americana e pelos meios políticos são os que buscam legitimar, com base na autoridade pessoal do presidente, práticas discursivas $^{7}$ antirreflexivas (MCCRIGHT \& DUNLAP, 2011). Uma segunda hipótese é a de que os tweets de Trump são distribuídos de forma a cumprir as funçôes textuais prototípicas desse tipo de prática discursiva, a saber, informar, interagir e fazer refletir (SANTOS, 2012).

Na seção a seguir, fazemos uma breve descrição das principais funçóes dos tweets em diferentes esferas sociais e apresentamos o corpus construído a partir das contas@POTUS, @WhiteHouse e @realDonaldTrump, classificando por temática e por distribuição diária os tweets postados no período de 01/05 a 06/06 de 2017. Em seguida, buscamos esboçar algumas análises dos tweets com base nas teorias de reflexividade e de legitimação social, visando contribuir para a compreensão dos modos de legitimaçáo do Twitter como uma fonte oficial da Casa Branca na administração de Donald Trump.

\section{BREVE DESCRIÇÃO DAS FUNÇÕES GERAIS DOS TWEETS E DO COMPORTAMENTO DAS CONTAS DA CASA BRANCA NO TWITTER: @POTUS, @WHITEHOUSE E @REALDONALDTRUMP}

Com o advento das avançadas tecnologias mediadas por computador, a interconectividade entre as pessoas e a acessibilidade a inúmeras formas de fontes de informação quebraram as práticas anteriores que privilegiavam certas mídias sobre outras. Uma dessas formas de tecnologia mediadas por computador é o Twitter, cuja missão é descrita em sua página da web (twitter.com) como "Dar a todos o poder de criar e compartilhar ideias e informaçôes instantaneamente, sem barreiras". Pode-se postar tweets a qualquer hora do dia simplesmente sendo um usuário reconhecido do site. Também é possível se inscrever para seguir os tweets de outros usuários.

O trabalho de Santos (2012), intitulado O pio do pássaro: uma análise das funçôes prototípicas do tweet, considerou a produção textual de cinco perfis sociais de usuários constantes dessa mídia digital. Ao referir-se ao histórico da criação do Twitter, ocorrida em 2006, mas consolidada a 
partir de 2009, a autora mostra que ele se torna um dos modelos de redes multimodais de sucesso em um momento especial do desenvolvimento tecnológico: o Twitter transforma-se em uma plataforma que possibilita, tanto quanto o Facebook, uma dinâmica de renovação contínua e coletiva de conteúdo simbólico. Santos (2012) mostra que a pergunta que deveria ser respondida no Twitter, à época de sua criação, era "O que você está fazendo?", de forma a servir como um ponto de encontro para grupos de pessoas conhecidas pelo usuário. A partir de 2007, segundo a autora, o Twitter agrega outras funcionalidades: a de disseminação da informação, com a criação da \#hashtag, e a de comentário sobre assuntos específicos. Outras funcionalidades foram sendo acrescentadas, como a de apresentar os sentimentos dos usuários. Ainda segundo a autora, em 2009 o slogan do Twitter passa a ser Compartilhe e descubra o que está acontecendo agora mesmo, em qualquer lugar do mundo. Em abril de 2011, o slogan mudou novamente para Siga seus interesses — atualizaçóes instantâneas de seus amigos, experts da indústria, celebridades favoritas e o que está acontecendo ao redor do mundo. Em 2012, mais uma pequena mudança no slogan: Descubra o que está acontecendo, agora mesmo, com as pessoas e organizaçôes que lhe interessam (SANTOS, 2012, p. 44).

Os resultados do trabalho de Santos (2012) mostram que as funçóes textuais prototípicas dos tweets são três: informar (o que o produtor está fazendo ou onde está ou, ainda, o que está acontecendo); interagir (com interlocutores conhecidos ou com o público em geral) e fazer refletir (sobre suas próprias práticas sociais e/ou linguagem e fazer o outro refletir sobre determinados temas ou práticas sociais). Essas funçóes não são aplicáveis tweet a tweet e nem de forma categórica para determinados perfis sociais. Ao contrário, se sobrepóem umas às outras e estão presentes, na grande maioria das vezes, nos mais diversos perfis sociais. Talvez essa multifuncionalidade seja uma das razóes pelas quais o Twitter é uma das redes multimodais de maior sucesso. Existem atualmente 313 milhóes de usuários ativos do site, e 82\% deles o acessam através de seus telefones celulares. Essas informaçóes estatísticas atestam a popularidade do site e a facilidade com que se pode postar e ler tweets.

Para compreender o contexto norte-americano do uso do Twitter por parte do atual presidente dos Estados Unidos, o site do jornal brasileiro $O$ Estado de S.Paulo explica que quem gerencia ambas as 
contas, @POTUS e @WhiteHouse, é a administração Donald Trump (O ESTADO DE S.PAULO, 2017). Sua conta pessoal, com tweets particulares, é a @realDonaldTrump. Já em outra reportagem (REDAÇÃO INTERNACIONAL, 2016), há uma explicação sobre a transferência das contas e de como ficaram arquivados os tweets feitos depois da saída do presidente Barack Obama. Segundo a matéria, mais de 11 milhóes de usuários seguem o perfil do presidente dos EUA no Twitter.

Para contextualizar a análise dos tweets produzidos por Donald Trump como forma de legitimação de determinadas práticas discursivas, mostramos na Tabela 1 os levantamentos das quantidades de tweets de cada uma das contas administradas pela Casa Branca (@POTUS e @WhiteHouse) durante o período de 01/05/17 a 06/06/17 e também da conta administrada pessoalmente por Trump (@realDonaldTrump). É importante destacar que os retweets são, em sua grande maioria, de autoria das mesmas autoridades: do vice-presidente, da primeira-dama Melania Trump, de diversos secretários de Estado e, às vezes, de outras autoridades. Assim, há tweets e retweets que se repetem nas três contas, pois o que o presidente tuíta na @realDonaldTrump aparece também na @POTUS e na @WhiteHouse, por exemplo.

Como neste artigo centraremos nossas análises na @realDonaldTrump, o comportamento das postagens nessa conta ao longo do período de 01/05/17 a 06/06/17 pode ser observado no Gráfico 1.

$\mathrm{Na}$ Tabela 2 e nos Gráficos 2 e 3, mostramos os levantamentos das principais temáticas dos tweets da conta administrada pessoalmente por Donald Trump (@realDonaldTrump) durante o período de 01/05/17 a 06/06/17.

\section{Tabela 1}

Número de tweets das contas da

Casa Branca no período de 01/05/17 a 05/06/2017.

\begin{tabular}{l|c|c}
\hline Conta & $\begin{array}{c}\text { Quantidade } \\
\text { de } \text { tweets }\end{array}$ & $\begin{array}{c}\text { Quantidade } \\
\text { de } \text { retweets }\end{array}$ \\
\hline @POTUS & 46 & 105 \\
\hline @WhiteHouse & 110 & 135 \\
\hline @realDonaldTrump & 161 & 22 \\
\hline Total & 733 & 460 \\
\hline
\end{tabular}




\section{Gráfico 1}

Comportamento das postagens na

conta@realDonaldTrump no período de 01/05/17 a 06/06/17.

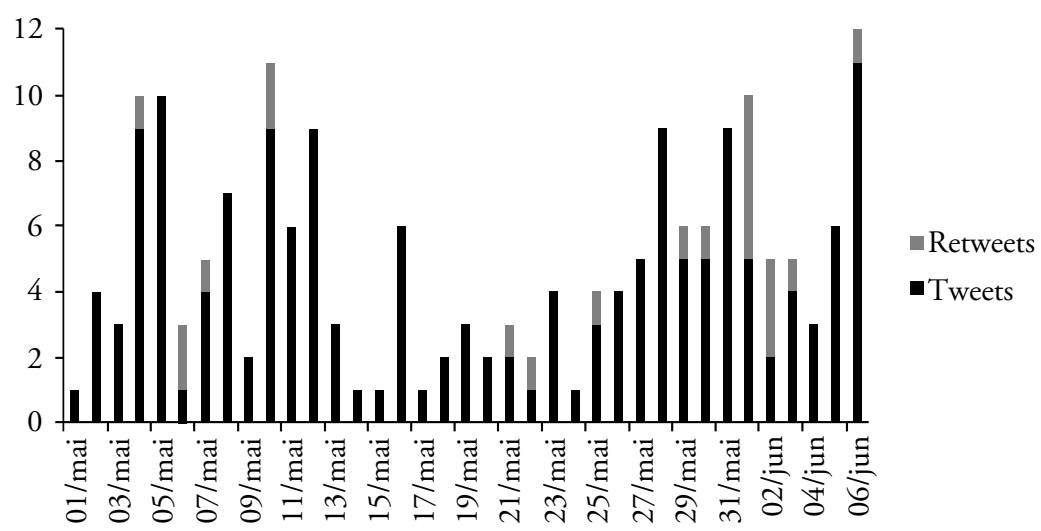

\section{Tabela 2}

Principais temáticas dos tweets da conta @realDonaldTrump no período de 01/05/17 a 06/05/17.

\begin{tabular}{l|c|c}
\hline Temáticas em @realDonaldTrump & $\begin{array}{c}\text { Quantidade } \\
\text { de tweets }\end{array}$ & $\begin{array}{c}\text { Quantidade } \\
\text { de retweets }\end{array}$ \\
\hline Eventos & 30 & 6 \\
\hline Açóes do governo Trump & 37 & 6 \\
\hline $\begin{array}{l}\text { Ataques/críticas aos democratas, a instituiçóes, } \\
\text { mídia comercial e figuras públicas }\end{array}$ & 58 & 2 \\
\hline Congratulaçóes/agradecimentos/mensagens de apoio & 13 & 0 \\
\hline Elogios aos republicanos & 2 & 0 \\
\hline Princípios/valores & 3 & 0 \\
\hline Brincadeiras & 4 & 0 \\
\hline Denúncias & 2 & 0 \\
\hline Travel Ban* & 3 & 0 \\
\hline Terrorismo & 9 & 1 \\
\hline Propagandas de governo & 0 & 2 \\
\hline Elogios às açóes de Trump & 0 & 5 \\
\hline Total & 161 & 22 \\
\hline
\end{tabular}

${ }^{*}$ Nesse contexto, trata-se da politica do presidente Donald Trump de bloqueio de fronteiras. Em outras palavras, a proibição de entrada nos Estados Unidos de pessoas que viajam a partir de determinados paises (em sua maioria mulçumanos). 


\section{Gráfico 2}

Principais temáticas dos tweets $\mathrm{da}$ conta@realDonaldTrump no período de 01/05/17 a 06/05/17.

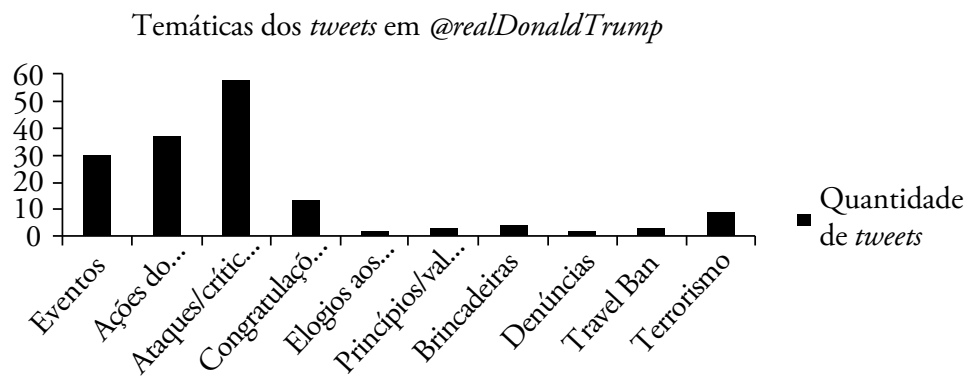

\section{Gráfico 3}

Principais temáticas dos retweets da conta@realDonaldTrump no período de 01/05/17 a 06/05/17.

Temáticas dos retweets em @realDonaldTrump

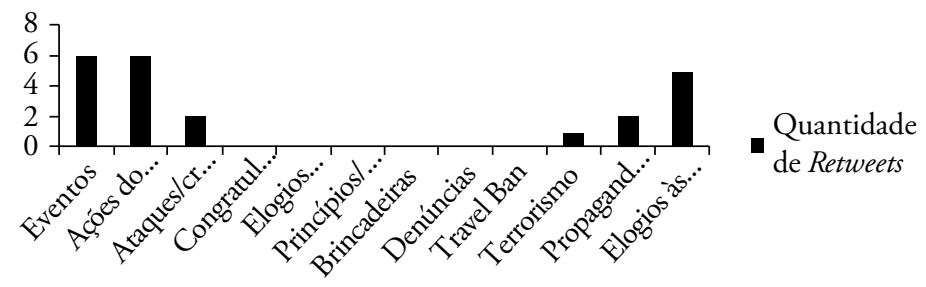

Uma questão importante relativa aos resultados apresentados anteriormente é o fato de que a distribuição da produção de tweets por parte do presidente Donald Trump no período analisado (Gráfico 1) alcança mais de 8 tweets por dia, em apenas 8 dias, do total de 37 dias. No entanto, se considerarmos a produçáo de 6 tweets por dia, esse número aumenta para 14 dias do total de 37 dias. Isto significa que a produção de tweets de Donald Trump náo parece exagerada em termos numéricos e que ele está longe de ser o "Twitter president", como o chamam na grande imprensa norte-americana. Se Trump merece esse título, é mais pelo uso antirreflexivo dessa mídia social como a maior autoridade dos Estados Unidos do que pela quantidade de textos postados em sua plataforma. É isso que pretendemos mostrar na próxima seção. 


\section{REFLEXIVIDADE E LEGITIMAÇÃO SOCIAL NAS TWEETSTORMS DE DONALD TRUMP}

A nosso ver, o que estamos presenciando com as "tweetstorms" do presidente Donald Trump é, ao mesmo tempo, a ruptura com as tradicionais formas de legitimação da ordem institucional e também de construção de categorias oficiais (BOURDIEU, 2013) e a elaboração, por meio de um processo específico de legitimação - a saber, o exercício da autoridade pessoal (VAN LEEUWEN, 2007) de Trump, angariada ao longo de muitos anos no interior da sociedade norte-americana - , de formas de legitimação de práticas de linguagem, temáticas e perspectivas antirreflexivas (ADAMS, 2006; MCCRIGHT \& DUNLAP, 2010; 2011), as quais estão sendo construídas como também válidas para serem performatizadas por um presidente da República. As "tweetstorms" seriam, então, uma ferramenta muito útil de oficialização e regularização (BOURDIEU, 2013; HANKS, 2008) dessas práticas discursivas, combatidas pela mídia tradicional norte-americana, pela mídia alternativa e pelo Partido Democrata. Nesse sentido, conforme vários autores do campo da Sociologia atestam, participamos atualmente de lutas por (des)legitimação de práticas discursivas e de atitudes sociais consideradas antirreflexivas.

$\mathrm{Na}$ esteira de um conjunto de discussóes sobre a tese da reflexividade estendida postulada por muitos autores do campo das Ciências Sociais, e compreendendo a reflexividade como um traço social da pósmodernidade, Adams (2006) afirma que, para os autores que abraçam essa tese, a reflexividade origina-se de uma diversidade de mudanças sociais, dentre elas, a expansão de estruturas e tecnologias de comunicação, a nossa exposição aos outros e a relativização de práticas socioculturais mais estabilizadas. No entanto, há muitas formas de compreender esse fenômeno.

Para autores clássicos como Giddens (1992) e Beck (1992), a reflexividade é um requisito necessário para a estruturação de identidades e subjetividades sociais. Para Bourdieu e Wacquant (1992), a reflexividade faz parte do habitus, sendo um constituinte fundamental, necessariamente requerido para a participação em determinados campos, como o científico e o acadêmico. Ainda para esses últimos autores, a re- 
flexividade se mostraria mais fortemente em tempos de crise. As críticas aos autores da tese da reflexividade estendida enfocam a fraca presença da estrutura social na teorização e as poucas explicaçóes sobre a diferenciação das experiências das pessoas em posiçôes diversas nos contextos sociais fortemente estruturados; além disso, alguns autores discutem a necessidade de uma maior sofisticaçáo na apresentação dos diferentes graus de reflexividade, liberdade e restriçóes em relação às sociedades em mudança. Outros autores (MCNAY, 1999; 2000; ADKINS, 2003; SWEETMAN, 2003; ADAMS, 2006), a partir de uma visada mais bourdieusiana do fenômeno da reflexividade na pós-modernidade, concordam com o fato de que, para mais pessoas, a reflexividade tenha se tornado habitual em função:

- da maior movimentação dos indivíduos entre os diversos campos sociais;

- de as fronteiras entre os campos estarem mais indefinidas;

- de os próprios campos estarem sujeitos a mudanças rápidas, abrangentes e contínuas (SWEETMAN, 2003, p. 541).

Para Adams (2006), o desenvolvimento dos estudos sobre reflexividade revela que ela apresenta um caráter muito mais complexo, ambíguo e contraditório do que as visadas ingênuas podem fazer crer. Ou seja, a reflexividade não se reduz, segundo o autor, a algum tipo de "metarreflexão internalizada" nem a um "potencial liberador contra um contexto do desmonte de estruturas sociais" (ADAMS, 2006, p. 521). Nesse sentido, o autor postula que a reflexividade performatizada pelos indivíduos em dada sociedade não é necessariamente transformadora, seja social, seja individualmente, e pode importar pouco se for separada de sua imediata incorporação a um específico e diferenciado contexto de uso de determinados recursos sociais. Nesse sentido, ele afirma:

Em um contexto de crescimento da polarização e de "mobilidade social descendente para amplos setores da anteriormente organizada classe trabalhadora" (Lash and Urry, 1994:145), para os pobres, a reflexividade compóe uma nítida falta de agência, dado que os indiví- 
duos são retirados de qualquer ordem social significativa e "alocados no interior de indefinidos, múltiplos, fraturados ou caóticos campos sociais" (Boyne, 2002:124), que não oferecem saídas (ADAMS, 2006, p. 524-525).

Ainda para esse autor, a teoria social deve contribuir para transformar as oportunidades individuais disponíveis em escolhas abertas para uma identidade relacional e autônoma, focando as formas pelas quais as oportunidades (ou a falta delas) gravitam na direçáo de determinados grupos sociais.

Já McCright e Dunlap (2010; 2011), ao reafirmarem as postulaçóes de outros teóricos da modernização reflexiva em relação à existência de "forças de reflexividade", tais como a ciência e o ambientalismo, que têm compelido as sociedades a confrontarem algumas ameaças à sua manutenção, também lembram que esses mesmos teóricos não têm considerado de maneira mais séria o que denominam "forças da antirreflexividade", representadas particularmente pelo setor industrial e pelos movimentos conservadores, que defendem a ordem capitalista mundial de qualquer crítica, negando a importância de grandes problemas sociais.

Os resultados dos trabalhos dos autores mostram que as elites ideológicas e partidárias nos Estados Unidos tornaram-se polarizadas em relação a uma ampla gama de questóes sociais, econômicas e culturais, incluindo temas ambientais como a mudança climática. Nesse sentido, os autores afirmam:

Essa dinâmica (de polarização) desafia os proponentes da modernização reflexiva, já que uma porcentagem crescente do público americano - e não apenas as elites conservadoras e industriais interessadas em si mesmas - negam tanto a evidência científica documentando a base antropogênica da mudança climática como também a necessidade de açóes para a melhora da situação. Essa difusão da antirreflexividade no interior da sociedade resulta em um decréscimo na vontade da populaçáo de conhecer uma enorme consequência negativa do capitalismo industrial. As guerras entre as culturas têm assim tomado uma nova dimensão, com muitas implicaçôes para a resiliência, a longo prazo, da sociedade (MCRIGHT \& DUNLAP, 2011, p. 180). 
Uma percepção difusa do papel antirreflexivo das postagens de Donald Trump como candidato pode ser observada na declaraçáo do cofundador do Twitter, Evan Williams. Uma matéria do Washington Post de 21 de maio de 2017, intitulada "Cofundador do Twitter. Peço desculpas se fomos responsáveis pela vitória de Trump para a Presidência”, traz a seguinte citação do executivo: "Eu pensei que, uma vez que todos pudessem falar livremente e trocar informaçóes e ideias, o mundo automaticamente seria um lugar melhor. Eu estava errado sobre isso. Se é verdade que ele [Trump] não seria presidente se não fosse pelo Twitter, então sim, desculpem” (SELK, 2017).

É importante dizer que uma das principais características temáticas dos tweets do atual presidente dos Estados Unidos são os ataques a membros da elite de democratas norte-americanos, incluindo os políticos, programas e jornalistas/meios de comunicaçáo considerados por ele como democratas, como os jornais Washington Post e The New York Times. Alguns exemplos de nosso corpus seguem:

(4) Desculpem, amigos, mas se eu tivesse confiado nas falsas notícias da CNN, NBC, ABC, CBS, washpost ou nytimes, eu teria tido ZERO chance de ganhar a CB (Casa Branca) $)^{8}(06 / 06 / 2017)$.

(5) Dems (democratas) estáo levando séculos para aprovar o meu pessoal, incluindo os Embaixadores. Eles não são nada mais do que OBSTRUCIONISTAS! Queremos aprovaçóes!' (05/06/2017).

(6) De novo, a história de que houve um conluio entre os Russos \& a campanha de Trump foi fabricada pelos Dems (democratas) como uma desculpa por terem perdido a eleição ${ }^{10}(12 / 05 / 2017)$.

Como é possível perceber, os ataques de Trump aos democratas e aos meios de comunicação produzem acusaçóes por meio de categorizaçóes (FALCONE, 2008) explícitas ("obstrucionistas") ou implícitas ("mentirosos", dado que "fabricam histórias" ou publicam "notícias falsas"). No entanto, os tweets do presidente também atacam autoridades de outros países, especialmente quando estão em um 
campo ideológico contrário ao dele. No contexto do ataque terrorista ocorrido em Londres, em 23 de maio de 2017, o presidente americano categorizou uma declaração ("Não há razão para alarme") do prefeito daquela cidade, Sadiq Khan, como uma "desculpa patética". Ele também pode atacar as próprias instâncias democráticas de seu país, como quando produziu um tweet, em 5 de junho de 2017, sobre a necessidade de executar sua proposta de proibição a viagens de pessoas de determinados países para os Estados Unidos, no qual afirma, ao final, que "as cortes são lentas e políticas". Por fim, Donald Trump pode atacar atores sociais importantes individualmente, como a candidata Hillary Clinton, que disputou com ele a eleição presidencial americana de 2016, chamando-a de "crooked", que, metaforicamente, significa "não confiável" ou "desonesta".

Se observarmos os resultados do levantamento quantitativo das temáticas dos tweets escritos pelo presidente Donald Trump, veremos que a maioria deles não constitui críticas ou ataques a pessoas, instituiçóes e/ou meios de comunicação comerciais, mas estão relacionados às principais funçóes textuais desempenhadas pelos tweets: informaçóes sobre os eventos dos quais participa; sobre as açóes do seu governo; sobre onde e com quem está etc., e a interação com audiências ou interlocutores específicos. Quando contamos os tweets que são centrados em elogios, congratulaçóes, manifestaçóes de apoio, agradecimentos, brincadeiras e explicitação de princípios e valores e os somamos às postagens em que Trump anuncia açóes de governo e sua participação em eventos diversos, temos, no período analisado, 78 contra 58 tweets centrados no ataque a adversários políticos.

Por fim, quando falamos que os tweets de Trump servem para legitimar açóes discursivas que buscam orientar e/ou reforçar no público uma atitude antirreflexiva, é porque também observamos o modo como a maioria das suas temáticas abraça agendas comprometidas com uma visão mercadológica do Estado, com a ordem capitalista industrial e com o sistema econômico que lhe é correspondente, buscando proteger esse sistema e essa ordem da acusação de promoverem consequências nefastas para a preservação da sociedade (ADAMS, 2006).

No período estudado, os tweets de Donald Trump tratam de temáticas que exemplificam vários aspectos dessa agenda. Um exem- 
plo são as postagens sobre uma das açôes do seu governo no período: a decisáo de os Estados Unidos se tornarem signatários ou não do Acordo de Paris sobre o meio ambiente. O presidente Donald Trump toma a decisão de não assinar o acordo, justificando que traria muitos "custos" ao trabalhador americano. Ser signatário do Acordo de Paris significaria, segundo a administraçáo Trump (em tweets postados pelo presidente, pelo vice-presidente e por políticos republicanos), pouco compromisso com a economia e os trabalhadores norte-americanos. $\mathrm{O}$ combate a perspectivas e propostas ambientalistas e a acordos transnacionais que buscam reduzir os efeitos do aquecimento global é um dos mais importantes itens da agenda antirreflexiva proposta pelos autores citados anteriormente. Outra temática bastante presente nos tweets do presidente é a que explicita o papel do Estado fundamentalmente como um bom lugar de negócios.

Os exemplos mencionados configuram tendências importantes, a serem observadas com mais vagar, de forma a se construir um quadro preciso dos tipos de ação e de temática que predominam em uma das práticas discursivas de maior impacto (tuitar), performatizada por uma das mais importantes autoridades do planeta.

\section{ALGUMAS CONCLUSÕES}

O contexto de enorme polarização presente na sociedade norte-americana é aprofundado tanto por meio da produção de determinados tweets pelo presidente Donald Trump como por meio da enorme repercussão de alguns de seus tweets produzida pela mídia comercial. Nesse sentido, é possível dizer que os debates existentes sobre os tweets de Trump dão visibilidade à polarização performatizada pelas elites ideológicas e partidárias norte-americanas sobre determinadas questóes sociais, dentre elas o tratamento de autoridades, figuras públicas e instâncias institucionais e o papel do Estado na sociedade. As configuraçóes temáticas dos tweets mostram que esse tipo de prática discursiva é um locus importante de observação das lutas por (des)legitimação de determinados valores sociais. Essas lutas acabam por constituir um verdadeiro "espetáculo", do qual partici- 
pam atores sociais dos mais diversos campos, da mídia comercial e digital americana e do campo político. Por fim, acreditamos que a maioria dos tweets do presidente Donald Trump, mesmo cumprindo funçôes prototípicas, legitima toda uma agenda antirreflexiva, tal como vem sendo discutido por sociólogos. Apesar de as temáticas da grande maioria dos tweets não serem repercutidas pela mídia comercial americana, elas são divulgadas (retuitadas) pelos seguidores do presidente, o que parece revelar um movimento de reconhecimento e consolidaçáo tanto da agenda postulada por Trump como de sua própria prática discursiva, pelo menos de parte expressiva do público norte-americano.

Sendo assim, as "tweetstorms" são objeto de lutas por legitimação, tanto pela administração Trump (que as legitima em função da posição de autoridade de quem enuncia, no caso, o presidente dos Estados Unidos) como pela grande mídia americana (que busca deslegitimar tweets específicos, especialmente aqueles que atacam a própria mídia, pessoas e/ou instituiçóes). A noção de reflexividade auxilia na compreensão das razóes pelas quais os tweets de Trump encontram "eco" na sociedade, dado que resultam de vozes/movimentos organizados e bem representados pelas temáticas e pontos de vista assumidos pelo presidente. Em suma, os processos de legitimação constituem-se como lutas contínuas por conquista de reconhecimento de determinadas agendas sociais, especialmente quando estão em jogo atores já investidos de grande autoridade, status e poder, como é o caso das elites norte-americanas - ou do presidente, que prefere a conquista do reconhecimento pela imposição de seu espaço e sua voz.

\section{REFERÊNCIAS}

ADAMS, M. Hybridizing Habitus and Reflexivity: Towards an Understanding of Contemporary Identity? Sociology, v. 40, n. 3, p. 511-528, 2006. https://doi. org $/ 10.1177 / 003803850663672$

ADKINS, L. Reflexivity: Freedom or Habit of Gender? Theory, Culture \& Society, v. 20, n. 6, p. 21-42, 2003. https://doi.org/10.1177/0263276403206002

BECK, U. Risk Society. Londres: Sage, 1992. 
BOURDIEU, P. A economia das trocas simbólicas. São Paulo: Perspectiva, 2004. . Questóes de sociologia. Rio de Janeiro: Marco Zero, 1983. . Razóes práticas. Campinas: Papirus, 2013.

BOURDIEU, P.; WACQUANT, L. An Invitation to Reflexive Sociology. Cambridge: Polity Press, 1992.

BYKOWICZ, J. Trump tweetstorms wash away White House press briefings. Business Insider, 2017. Disponível em: shttp://www.businessinsider.com/ ap-trump-tweetstorms-wash-away-white-house-press-briefings-2017-6>. Acesso em: 5 jul. 2017.

FALCONE, K. (Des)legitimação: açóes discursivo-cognitivas para o processo de categorização social. Tese (Doutorado em Letras) - Universidade Federal de Pernambuco, Recife, 2008.

GARAY, A.; INIIGUEZ, L.; MARTÍNEZ, L.M. La perspectiva discursiva en psicología social. Subjetividad y Procesos Cognitivos, p. 105-130, 2005.

GIDDENS, A. The Transformation of Intimacy. Cambridge: Polity Press, 1992.

HANKS, W.F. Lingua como prática social: das relaçóes entre Bourdieu e Bakhtin. São Paulo: Cortez, 2008.

McCRIGHT, A. \& DUNLAP, R. Anti-Reflexivity: The American Conservative Movement's Success in Undermining Climate Science and Policy. Theory, Culture, and Society, v. 27, n. 2-3, p. 1-34, 2010. DOI: $10.1177 / 0263276409356001$

$\&$ . The Politicization of Climate Change and Polarization in the American Public's Views of Global Warming, 2001-2010. The Sociological Quarterly, v. 52, p. 155-194, 2011. https://doi.org/10.1111/j.15338525.2011.01198.x

McNAY, L. Gender and Agency. Cambridge: Polity Press, 2000.

Gender, Habitus and the Field: Pierre Bourdieu and the Limits of Reflexivity. Theory, Culture and Society, v. 16, n. 1, p. 95-117, 1999. https://doi. org/10.1177/026327699016001007

O ESTADO DE S.PAULO. Administração de Donald Trump assume site da Casa Branca. O Estado de S.Paulo, 2017. Disponível em: <http://internacional. estadao.com.br/noticias/geral,administracao-de-donald-trump-assume-site-dacasa-branca,70001636114>. Acesso em: 11 jun. 2017. 
REDAÇÃO INTERNACIONAL. Equipe da Casa Branca explica como será transição de redes sociais para a nova presidência. O Estado de S.Paulo, 2016. Disponível em: <http://internacional.estadao.com.br/blogs/eua-2016/ equipe-da-casa-branca-explica-como-sera-transicao-de-redes-sociais-para-anova-presidencia/>. Acesso em: 11 jun. 2017.

SANTOS, L. O pio do pássaro: uma análise das funções prototípicas dos tweets. Dissertação (Mestrado) - Universidade Estadual de Campinas, Campinas, 2012.

SELK, Avi. Twitter co-founder: I'm sorry if we made Trump's presidency possible. The Washington Post, 2017. Disponível em: shttps://www.washingtonpost.com/ news/the-switch/wp/2017/05/21/twitter-co-founder-im-sorry-if-we-made-trumpspresidency-possible/?utm term $=.2 \mathrm{~d} 5 \mathrm{da} 9 \mathrm{~b} 177 \mathrm{ef}>$. Acesso em: 22 maio 2017.

SWEETMAN, P. Twenty-first Century Disease? Habitual Reflexivity or the Reflexive Habitus. Sociological Review, v. 51, n. 4, p. 528-549, 2003. https://doi.org/10.1111/j.1467-954X.2003.00434.x

TRUMPTWITTERARCHIVE. Disponívelem: $\leq$ http://www.trumptwitterarchive. com/>. Acesso em: 19 abr. 2018.

VAN LEEUWEN, T. Legitimation in discourse and communication. Discourse and Communication, v. 1, p.91-112,2007. https://doi.org/10.1177/1750481307071986

\section{NOTAS}

1. O site Forbes.com analisou de perto os 20 milhóes de seguidores alegados em janeiro de 2017 e descobriu que um número mais provável era de 3 milhões de seguidores nos Estados Unidos. O jornalista Rob Salkowitz relata que esta população representa $52 \%$ do sexo masculino, $48 \%$ do sexo feminino e a maior parte na faixa etária de 24 a 34 anos. Aproximadamente 28\% possuem 35 a 44 anos e 18\%, mais de 45 anos. Cerca de 360.000 deles tuítam mais de 15 vezes por mês, o que indica atividade razoavelmente elevada de Twitter. Eles se identificam com os termos "família", "marido", "Deus" e "cristão". Outros que seguem os tweets de Trump são pessoas de negócios, principalmente de 35 a 44 anos e de Nova York, além de Califórnia, Chicago, Flórida e Dallas.

2. Original: Maybe the best thing to do would be to cancel all future press briefings and hand out written responses for the sake of accuracy? A tradução de todos os tweets citados é de nossa responsabilidade.

3. Original: James Comey better hope that there are no "tapes" of our conversations before he starts leaking to the press. 
4. Original: This is the single greatest witch hunt of a politician in American history.

5. Original: There's no vetting by lawyers (at least, not that deputy White House press secretary Sarah Huckabee Sanders is aware of), there's no vetting by communications staff. It's just a president and his iPhone, speaking for the entire White House. Disponível em: <https:/www.washingtonpost.com/news/the-fix/wp/2017/06/06/ sean-spicer-just-settled-it-we-should-all-pay-attention-to-trumps-tweets/?utm_ term=.0f94b2e19159\&wpisrc=nl_az_most\&wpmk=1>. Acesso em: 10 jun. 2017.

6. Uma breve discussão sobre esse conceito é feita na seção 3 deste artigo.

7. Em consonância com uma perspectiva de base sociocognitiva, assumiremos ao longo deste projeto a concepção de discurso resumida na formulação de Garay, Ińiguez e MartÍnez (2005, p. 110-111): "Um conjunto de práticas linguísticas que mantém e promove certas relaçóes sociais”. O interesse desse grupo de pesquisadores é investigar como os próprios atores sociais elaboram suas interaçóes sociais e verbais a partir de perspectivas variáveis e diversas do mundo social, considerando que a "orientação do discurso para funções específicas é uma indicação de seu caráter construtivo" (GARAY; INIIGUEZ; MARTINEZ, 2005, p. 111). O grupo também dialoga com autores que consideram centralmente três premissas: a do interesse sobre como as pessoas constroem a realidade social; a da consideração da linguagem não como uma descrição da realidade, mas como uma construção dessa realidade; e a da compreensão da linguagem como uma prática social (GARAY; INIIGUEZ; MARTINEZ, 2005, p. 112).

8. Original: Sorry, folks, but if I would have relied on the Fake News of $C N N, N B C, A B C$, CBS, washpost or nytimes, I would have had ZERO chance winning WH. (06/06/2017)

9. Original: Dems are taking forever to approve my people, including Ambassadors. They are nothing but OBSTRUCTIONISTS! Want approvals! (05/06/2017)

10. Original: Again the story that there was collusion between the Russians \& Trump campaign was fabricated by Dems as an excuse for losing the election. (12/05/2017)

Recebido em 02 de agosto de 2017.

Aceito em 23 de março de 2018.

(C) 2018 Centro de Estudos Educação e Sociedade - CEDES Este é um artigo de acesso aberto distribuído nos termos de licença Creative Commons. 